\title{
On Williamson and Simplicity in Modal Logic*
}

Theodore Sider Canadian fournal of Pbilosophy 46 (2016): 683-98

According to Timothy Williamson, we should accept the simplest and most powerful second-order modal logic, and as a result accept an ontology of "bare possibilia". This general method for extracting ontology from logic is salutary, but its application in this case depends on a questionable assumption: that modality is a fundamental feature of the world.

\section{Necessitism}

The central thesis of Williamson's wonderful book Modal Logic as Metaphysics is "Necessitism". Put roughly and vividly, Necessitism says that everything necessarily exists. Williamson himself avoids the predicate 'exists', and formulates the view thus:

Necessitism $\forall x \square \exists y y=x$ ("Everything necessarily is something")

Williamson's scruples about 'exists' are reasonable but sometimes require tortured prose, so, choosing beauty over function, I will use the E-word. (But let it be understood that by " $x$ exists" I just mean that $x$ is identical to somethingwith quantifiers "wide open".)

The considerations favoring Necessitism also lead Williamson to accept the Barcan schema (as well as its converse):

\section{Barcan schema $\diamond \exists x A \rightarrow \exists x \diamond A$}

So if there could have been a child of Wittgenstein, then there in fact exists something that could have been a child of Wittgenstein.

This thing that could have been a child of Wittgenstein: what is it like? What are its properties? Well, it has the modal property of possibly being a child of Wittgenstein. And logic demands that it have certain further properties, such as the property of being self-identical, the property of being green if it is green, and so forth. And since Wittgenstein in fact has no children, it has the property of not being a child of Wittgenstein. But it has no other properties beyond these sorts. It is not a human being. It has no physical properties such

*Thanks to Karen Bennett and Timothy Williamson. 
as mass or spatial location. ${ }^{1}$ It is in a sense nonconcrete (which is not to say that it is abstract in any positive sense), a "bare possibilium".

Similarly, although Williamson denies that anything could have failed to exist, he allows that an object like me, say, could have failed to be concrete. I could have been a bare possibilium.

Williamson's ontology, then, includes vastly more entities than we ordinarily accept. It is not contingent what entities there are; what is contingent is which entities are concrete.

\section{Williamson's argument}

Williamson's argument for the Barcan schema and Necessitism is that they are implied by the best modal logic — by the modal logic that best combines various theoretical virtues such as simplicity and strength. An older argument along these lines, versions of which have been defended by Linsky and Zalta (1994, 1996), and by Williamson himself (1998; 2002), claims that the Barcan schema and Necessitism hold in the best first-order quantified modal logic. ${ }^{2}$ Contingentists - those who believe that things can exist contingently-have developed quantified modal logics that do not have these consequences. But Necessitists argue that these logics are more complex, or are otherwise inferior to, necessitist quantified modal logic.

What do the contingentist logics look like, and what challenges do they face? Model theoretically, they are based on Kripke models with variable domains. This approach faces the formal challenge of assigning truth values to formulas in worlds where objects denoted in the formula do not exist, and the philosophical challenge of saying how a variable-domain Kripke model can be an intended model if necessity and possibility do not reduce to facts about possible worlds (as most Contingentists agree they do not), and if the domains of nonactual worlds in the model contain entities that are not in the domain of its actual world.

Proof-theoretically, the challenges may be brought out by the following argument. Let $t$ name me, and consider the following:
I. $\vdash t=t$
(reflexivity of identity)
2. $\vdash \exists y y=t$
( $\mathrm{I}$, existential generalization)

\footnotetext{
${ }^{1}$ Whether it has causes and effects depends on what we say about causation by absence.

${ }^{2}$ See also Cresswell (I99i).
} 


$$
\text { 3. } \vdash \square y y=t \quad \text { (2, necessitation) }
$$

The conclusion says that I necessarily exist. So Contingentists will want to resist the argument. That means rejecting one of the steps. They may, for instance, restrict existential generalization by embracing a free logic, or they may restrict the rule of necessitation. But Necessitists then argue that these restrictions make the logic more complex, or are not independently philosophically motivated, or weaken the logic in unwanted ways.

An important part of Williamson's case for Necessitism is a powerful new development of this style of argument, for second-order rather than first-order quantified modal logic. Nonmodal second-order logic usually includes the following comprehension principle:

Nonmodal comprehension $\exists X \forall x(X x \leftrightarrow A)$

where any string of universal quantifiers may be prefixed to the result and $A$ may be replaced with any formula. ${ }^{3}$ When we add modal operators to the language, the question then arises of how to strengthen the comprehension principle. Williamson's preferred strengthening is this:

\section{Modal comprehension $\exists X \square \forall x(X x \longleftrightarrow A)$}

where any combination of universal quantifiers and occurrences of $\square$ may be prefixed. (Note: the second-order quantifiers in this discussion are not to be given Boolos's plural interpretation; they are "intensional" second-order quantifiers.)

Modal comprehension implies this:

\section{Haecceities $\forall y \square \exists X \square \forall x(X x \longleftrightarrow x=y)$}

Haecceities may be paraphrased, somewhat naughtily, thus: "for every object, $y$, it's necessary that there exists a property that, necessarily, is instantiated by something iff that something is $y$ "; or, more succinctly: "for every object, it's necessary that there is a haecceity of that object". (The naughtiness is that the irreducibly second-order quantification in Haecceities sounds like first-order quantification over properties in the paraphrases.)

Williamson then argues that Contingentists ought to reject Haecceities; the crux of the argument is this:

\footnotetext{
${ }^{3}$ This is the monadic case of a more general principle. $X$ may not be free in $A$; $A$ will in general contain $x$ free, and may contain further free variables, which may be bound to the prefixing quantifiers.
} 
Even if I had never been, by [Haecceities] there would still have been a property tracking me (and only me). But how can it lock onto me in my absence? In those circumstances, what makes me rather than something else its target? (p. 269)

This objection to Haecceities is similar to Kit Fine's (1985) objection to Alvin Plantinga's (1976) individual essences. One might question whether Williamson's objection is as powerful as Fine's, because of a difference between their targets. What Fine objected to was Plantinga's postulation of an entity, a property, that would track me (in the sense of necessarily being instantiated by something iff that something is me) even if I didn't exist, whereas Haecceities doesn't say that there would exist any such entity. It doesn't talk about properties at all (despite the naughty paraphrase); the variable $X$ in Haecceities is irreducibly second-order. Still, the second-order $\exists X$ is meant to be a sort of existential quantification, after all; the strength of Fine's first-order argument arguably carries over to Williamson's second-order argument.

Thus Contingentists are under pressure to restrict the Modal comprehension principle. But Williamson then argues that all Contingentist-friendly restrictions would badly restrict second-order modal logic.

One Contingentist strategy would be to revert to the Nonmodal comprehension principle, but now allow modal operators to occur in the prefixes. What a comprehension principle does is imply the existence of a property corresponding to an arbitrarily chosen formula; the envisioned restriction implies that the correspondence is merely "intra-world" rather than inter-world. And therein lies its fatal weakness, according to Williamson. Second-order quantification (of the type Williamson is discussing) is the analog of first-order quantification over properties in the "abundant" sense. ${ }^{4}$ Thus our secondorder modal logic ought to imply, for instance, that properties are closed under conjunction: that for any properties $Y$ and $Z$, there exists a conjunction of those properties. A conjunction of $Y$ and $Z$ is a property that, necessarily, is instantiated by something iff that thing instantiates both $Y$ and $Z$; thus we want the following claim:

Conjunction $\forall Y \forall Z \exists X \square \forall x(X x \leftrightarrow(Y x \wedge Z x))$

But note that Conjunction expresses an inter-world, not merely intra-world, correlation, between the property $X$ and the chosen formula $Y x \wedge Z x . X$ must

\footnotetext{
${ }^{4}$ See Lewis (I986, pp. 59-60), who emphasizes the need to recognize both abundant and "sparse" properties.
} 
be necessarily such as to be instantiated when and only when $Y$ and $Z$ are instantiated. Conjunction is implied by Williamson's Modal comprehension principle, but not by the weakened principle. The weakened principle merely implies such claims as:

$$
\begin{aligned}
& \forall Y \forall Z \exists X \forall x(X x \leftrightarrow(Y x \wedge Z x)) \\
& \square \forall Y \forall Z \exists X \forall x(X x \leftrightarrow(Y x \wedge Z x)) \\
& \square \square \forall Y \forall Z \exists X \forall x(X x \leftrightarrow(Y x \wedge Z x))
\end{aligned}
$$

etc.

in which the property $X$ whose existence is guaranteed is merely the "intraworld conjunction of $Y$ and $Z$ ". The second formula, for instance, says that (to put it in possible worlds talk), in any possible world $w$, for any properties $Y$ and $Z$ in $w$, there exists in $w$ a property $X$ that is in $w$ instantiated when and only when both $Y$ and $Z$ are instantiated, but this leaves open that in other worlds $v$, it's not the case that $X$ is instantiated when and only when $Y$ and $Z$ are both instantiated.

Williamson considers other weakenings of Modal comprehension, but in each case he argues that Contingentist-friendly weakenings "[prevent] secondorder logic from adequately serving the logical and mathematical purposes for which we need it" (p. 288) - those purposes demanding an abundant conception of properties in a modal context.

How might one resist this argument? One might meet it head-on, either by i) defending Haecceities against the Williamson/Fine objection, or ii) conceding that Haecceities is false and seeking out some weakened comprehension principle that does not imply Haecceities but nevertheless is strong enough for the desired applications of second-order logic. I won't pursue either route here. (I don't see how to pursue ii), and i) strikes me as being metaphysically ugly.) Instead I will discuss two ways to resist the argument indirectly. In the next section I will consider-but reject—-the possibility of accepting the argument's conclusion but "defanging" that conclusion by distinguishing fundamental from nonfundamental existence. Then in the final section I will argue that if modality is not a fundamental feature of the world, there is no presumption that second-order modal logic be simple and strong; thus we can simply reject the demand for a simple and strong comprehension principle. 


\section{Fundamental and nonfundamental existence}

Some ontologists distinguish between existence and fundamental existence. ${ }^{5}$ The distinction is believed to resolve the tension between a pair of conflicting pressures: pressure (which can come from various sources) to increase ontology, and pressure from Occam's razor to contract ontology. The resolution is achieved by increasing ontology while minimizing fundamental ontology, and by claiming that Occam's razor applies only to fundamental ontology. ${ }^{6}$ For example, we might bow to inflationary ontological pressure by accepting the existence of shadows, while appeasing Occam by denying that there fundamentally are any such things. Fans of this distinction may be tempted to apply it here, to say that Williamsonian entities exist but don't fundamentally exist. Thus we have our cake and eat it too: denying the fundamental existence of Williamsonian entities appeases Occam, while accepting their existence lets us avoid challenging Williamson's argument head-on; that argument, which concerns existence, not fundamental existence, may simply be accepted.

But consider a restated version of Williamson's argument in which all quantifiers are stipulated to express fundamental existence. The plan was to reject the fundamental existence of Williamsonian entities; thus the restated argument must be rejected. But the plan was also to accept Williamson's original argument. Thus the plan is successful only if the restated argument is weaker than the original argument. But in fact I think that restating the argument in terms of fundamental existence strengthens it: as we'll see in the next section, it's natural to think that the case for simplicity in modal logic is strongest if all the concepts involved are fundamental ones.

Furthermore, even setting this aside, facts about what exists nonfundamentally must, like all nonfundamental facts, be somehow "based" or "grounded" in fundamental facts. So if Williamsonian entities exist but nonfundamentally so, facts about them must be grounded in facts that do not involve the existence of such entities. But it's unclear whether appropriate grounding facts can be found.

In some cases of nonfundamental existence, it's easy to see what the grounding base might be. Facts about shadows, for instance, might be said to be grounded in certain facts about things and their relationships to light sources

\footnotetext{
${ }^{5}$ See Dorr (2005, 2007); Fine (2009); Schaffer (2009); Sider (2009, 201 I, chapters 7-9); Cameron (2010).

${ }^{6}$ On the latter claim see Schaffer (2009, p. 36r); Sider (20 I I, p. I69, note Io); Bennett (2017, chapter 7).
} 
and backgrounds. Such facts are fit to ground putative facts about shadows because there is no apparent "metaphysical gap" between them and the facts about shadows; the existence of my shadow is "nothing over and above", it's said, my existence and my relations to light sources and backgrounds. Many would also say that there is no metaphysical gap between the existence of a mereological sum and the existence of its parts. There is, however, a metaphysical gap between, for instance, our evidence for subatomic particles and the existence of those particles; thus the existence of subatomic particles is not grounded in our evidence for them.

So, can we find a grounding base for the existence of Williamson's nonconcrete entities? Those entities are certainly not composed (in any relevant sense) of more mundane entities. Nor are there more mundane entities that stand to Williamsonian entities as I stand to my shadow, or as holes stand to hole-linings, to take another example. If a grounding story is to be told here, it cannot be parallel to the stories for sums or shadows or holes.

The best bet for a grounding base would seem to be certain modal facts. ${ }^{7}$ Suppose a certain knife blade $B$ and knife handle $H$ are manufactured, but are never joined to make a knife. They could have been so joined: there could have existed a knife made of $B$ and $H$. Thus, according to Williamson, there exists a (nonconcrete) object that could have been a knife made of $B$ and $H$. Indeed, it's plausible that there is just one such object (Williamson, 2000, p. 335). Here a ground of the existence of this Williamsonian entity suggests itself: the modal fact that there could have existed a knife made of $B$ and $H$. (According to this proposal, notice, an existential fact, that there exists an entity of such-and-such a type, can be grounded in a fact that is modal rather than existential in form: that there could have existed an entity of such-and-such a type. Nonfundamental existence would thus be quite unlike fundamental existence in its underlying metaphysical nature.)

But the case of the possible knife made from $B$ and $H$ is special in a crucial way: though the possible knife is not concrete, it has concrete "anchors" in $B$ and $H$ since it can be uniquely specified as the possible knife that could have been made from those concrete objects. In other cases there are no such concrete anchors. Suppose there are only finitely many subatomic particles: $a_{1} \ldots a_{n}$. Then, assuming it is possible that there exists another subatomic particle distinct from $a_{1} \ldots a_{n}$, the Barcan schema implies the existence of something that could have been a subatomic particle distinct from $a_{1} \ldots a_{n}$; and given other modal

\footnotetext{
${ }^{7}$ Compare Fine (1977).
} 
principles Williamson accepts-the necessity of distinctness and the "B" schema from propositional modal logic - this something must in fact be distinct from $a_{1} \ldots a_{n}$. Indeed, Williamson will admit the existence of infinitely many such possible subatomic particles, since for any finite number of them $b_{1} \ldots b_{m}$, it's possible that there exists a subatomic particle distinct from $a_{1} \ldots a_{n}$ and also from $b_{1} \ldots b_{m}$. Letting $b_{i}$ be any one of these nonconcrete possible subatomic particles, it's then hard to see what ground there might be for the existence of $b_{i}$, because there is no concrete anchor for $b_{i}$ as opposed to the other $b_{j}$ s. For instance, the modal fact that there could have existed a subatomic particle distinct from $a_{1} \ldots a_{n}$ seems to be an unfit ground for the existence of $b_{i}$, since if it were, it would presumably also be the ground for the existence of every other $b_{j}$; but surely these facts should all have different grounds. ${ }^{8}$

Although the modal fact that there could have existed a subatomic particle distinct from $a_{1} \ldots a_{n}$ seems unfit to ground singular existence-facts about any particular $b_{i}$, it seems more fit to ground the general ${ }^{9}$ fact that there exists some possible subatomic particle or other distinct from $a_{1} \ldots a_{n}$. So I suppose there is room for a position that denies the existence of singular facts about "unanchored" entities, admitting only general facts about them. Still, it faces some questions. i) Is it well-placed to accept Williamson's argument that we need his strong comprehension principles; can we get by in second-order modal logic with only these general facts? ii) How will it resist the argument that if there is a general fact that there exists an $F$, then there must also exist a particular fact of the form $a$ is $F$ ? iii) Let $a$ be something that, in fact, fundamentally exists-a subatomic particle, say. Although a exists necessarily, it could have been nonconcrete; and if it had been nonconcrete, there would have been various singular facts about it (it would have existed, been possibly concrete, and so forth). But $a$ would then have been unanchored, and wasn't the idea to reject singular facts about unanchored things? ${ }^{10}$

\footnotetext{
${ }^{8}$ This general style of kind of argument-requiring different grounds for different facts in certain cases-is pursued by Shamik Dasgupta (2014, p. 573) in a different case. There is, though, a hard question of exactly when distinct facts should be required to have distinct grounds, since the requirement is not correct in general-most friends of ground would admit, for instance, that the fact that $P$ can ground both $\sim \sim P$ and also $\sim \sim \sim P$. (This hard question, in my view, is symptomatic of a problematic feature of the "conditional" notion of ground, as opposed to "biconditional" level-connecting concepts. See Sider $(2013 a, b)$.)

${ }^{9} \mathrm{Well}$, the fact is partially singular since it involves $a_{1} \ldots a_{n}$, but what's important is that it is general insofar as it involves nonconcreta.

${ }^{10}$ The rejection might be restricted to actually unanchored things. This would be in the spirit
} 


\section{The scope of simplicity+strength arguments}

My plan for the remainder is to challenge Williamson's argument on methodological grounds. Necessitist second order logic would indeed be simpler and stronger than the contingentist variety, I grant; but, I will argue, we can nevertheless reject that logic since the presumption that second-order modal logic be simple and strong is weak. However, I believe that Williamson's general methodology — his view of how to choose a logic, and of the bearing of this choice on metaphysics and ontology in general-is correct. Williamson lays out his methodology right from the start, in the first paragraph of the book's preface:

The title of this book may sound to some readers like Good as Evil, or perhaps Cabbages as Kings. If logic and metaphysics appear disjoint, the reason is not just the lingering spell of a logical positivist conception of metaphysics as cognitively meaningless and logic as cognitively meaningful but analytic. Many contemporary philosophers who acknowledge metaphysics as continuous with the rest of science are still inclined to assign logic a more special status. They see it as a neutral referee of disputes between scientific theories, including metaphysical theories, blowing the whistle when the rules are broken, not as a disputing party in its own right. If so, logic says nothing over which there could be such a dispute, on pain of non-neutrality; thus logical theories are quite different in status from scientific theories. This book is written in the contrary conviction that, just as metaphysics is much more like the rest of science than was once thought, so too is logic. Indeed, one role for logic is to supply a central structural core to scientific theories, including metaphysical theories, in essence no more above dispute than any other part of those theories.

I couldn't agree more. And from this point of view, the theoretical pressure to accept a simple yet powerful logic does not differ in kind from the theoretical pressure to accept simple yet powerful laws of nature. David Lewis's On the Plurality of Worlds had a massive impact on the way metaphysics was practiced, even on those who did not accept its conclusion, because of the methodology it championed: an approach to ontology in the spirit of the indispensability

of "nonserious actualism" (Plantinga, I983; Fine, I985; Salmon, I998), and would arguably not be ad hoc: given $a$ 's actual concrete existence, we can single it out and make modal claims about it in particular-even the claim that it could have been nonconcrete. (If $a$ had been nonconcrete, what fact would have grounded its existence? Answer: "The singular modal fact that a could have existed fundamentally!"-more of the same nonseriousness.) 
argument for mathematical entities. Williamson's book will, I predict, have a similar impact, even amongst those who remain unconvinced of Necessitism, because of its methodology of choosing metaphysical positions using logical considerations.

On, though, to my objection. I grant the analogy between the presumption of simple, powerful laws of nature and the presumption of a simple, powerful logic. But it's not true that there is a presumption of simple and powerful statements governing just any concepts. While such a presumption exists for some concepts-concepts of physics, for instance-there is surely no such presumption for the concepts of lying, bachelorhood, or games. It would be misguided to let the simplicity and strength of a proposed "logic" of lying, bachelorhood, or games carry much weight, if it conflicted with our otherwise reasonable beliefs about those domains. If someone boldly conjectured that all utterances of falsehoods are lies, we would not downgrade the importance of the obvious counterexamples (innocent mistakes, non-assertive utterances...) by saying "yes, but the proposed 'logic' is so simple that we should reconsider whether the alleged counterexamples are really genuine". ${ }^{11}$

Also, without any restriction on the concepts involved, a presumption in favor of simplicity and strength will give no guidance. As is familiar from Nelson Goodman (1955), if such a presumption using the concepts of blue and green were accompanied by equally strong presumptions using arbitrarily chosen other concepts-such as his grue and bleen - then the presumptions as a whole would yield no guidance for what to believe.

Williamson's argument succeeds only if the concepts of second-order modal logic are like those of physics, and unlike lying, bachelorhood, games, and grue and bleen, in being "presumptively simple"-in being concepts for which there is indeed a presumption of simple and strong generalizations. I'm going to argue that they are not. In doing so I am going to assume a particular metaphysics, and a particular connection between that metaphysics and epistemology. A similar story could, I hope, be told under other assumptions, but it's best to proceed under some definite assumptions. Roughly put, my claim is that the concepts of second-order modal logic are presumptively simple only if modality is metaphysically fundamental; and it isn't. ${ }^{12}$

Now, simplicity arguments are certainly not confined to reasoning about what is fundamental. Simplicity arguments are routinely used by detectives,

\footnotetext{
${ }^{11}$ See Weatherson (2003) for a discussion of a number of related issues.

${ }^{12}$ On metaphysical fundamentality see Sider (20 I I).
} 
hunters, and archaeologists, not just physicists. ${ }^{13}$ A detective prefers the simple hypothesis that the murder was committed by a single person, unless and until the evidence demands a more complex explanation; and the concepts of criminology are of course not fundamental.

But simplicity reasoning in such everyday cases need not be underwritten by any ultimate presumption concerning the concepts involved. ${ }^{14}$ By "ultimate" I mean epistemically ultimate; an ultimate presumption is thus a principle or element of epistemology (for instance a prior probability distribution, in a Bayesian setting) that is not derived from any further principle or element of epistemology. Suppose there is an ultimate presumption in favor of simplicity in physics. This alone would underwrite simplicity reasoning in chemistry, for example, because of the manner in which chemical properties are based in physics. (Understand "basing" however you like.) A presumption of simplicity in physics means that it's rational to assume a priori that the world is likely to be physically simple, that certain sorts of physical complexity are a priori highly unlikely. We assume that it's a priori highly unlikely for there to be a sudden, huge, isolated exception to otherwise simple physical generalizationsall particles in the universe suddenly undergoing discontinuous, drastic and haphazard changes to their positions, masses, and charges, say. But such an occurrence would also constitute a sudden, huge, and isolated exception to otherwise simple chemical generalizations, and thus would count as chemical complexity as well. More generally: any sudden, huge, isolated exception to otherwise simple chemical generalizations would require some such physical complexity or other; thus we assume a priori that these exceptions are unlikely. ${ }^{15}$

It's a reasonable guess that something like this holds more generally. Ordinary appeals to simplicity, such as by detectives, hunters, and archaeologists, do not require epistemically ultimate presumptions of simplicity for the concepts they involve. Given a presumption of simplicity in physics, there is no need for a fundamental presumption of simplicity in criminology, hunting, or archaeology. When judging that there was probably just a single murderer, a detective has her past experience to work with: murderers have generally acted

\footnotetext{
${ }^{13}$ As Williamson pointed out in response to a draft of this paper.

${ }^{14}$ See also Bennett (2017, chapter 7).

15 "But what if one doesn't know how, or even that, chemistry is based in physics?"-I'm thinking of the epistemology here in an "externalist" way. The believer needn't compute what she's a priori entitled to believe about chemistry from some initial assumptions about physics. The picture is rather that certain possible worlds are a priori more likely, and that those worlds are in fact physically and hence chemically simple.
} 
alone, and when multiple murderers did conspire, they generally left distinctive traces that are in this case absent. I grant that some epistemically ultimate bias toward simplicity is needed to move from this evidence about the past to the conclusion that there is just one murderer at work here in the present, but surely that bias needn't be at the level of criminology: the world would need to be unnecessarily physically complex for there to have been two or more murderers. Detectives can even make simplicity-arguments using concepts such as lying, bachelorhood, or games (or even grue) without an ultimate presumption of simplicity for such concepts. The simplest hypothesis available to a detective might be that one of her suspects has lied, but the sort of simplicity ultimately at issue is at the level of physics.

Williamson's argument assumes that there are likely to be simple laws governing the concepts of second-order modal logic. If those concepts had an appropriate basis in physical concepts, then his argument could be underwritten by an ultimate bias in favor of physical simplicity, just like the arguments of detectives, hunters, and archaeologists. But this seems very unlikely.

I've been writing as if ordinary simplicity reasoning requires only an ultimate presumption of physical simplicity, but probably that's not quite right; no doubt we need to recognize other "ultimately simple" concepts-other concepts for which there are ultimate presumptions of simple and strong generalizations. ${ }^{16}$ Certain mathematical concepts, and the concepts of first- and perhaps even second-order logic, are likely candidates. But even when the bias toward physical simplicity is thus enhanced, it still seems unable to underwrite Williamson's argument, since it seems unlikely that modal concepts have an appropriate basis in physical, mathematical, and (nonmodal) logical concepts.

It's not enough that modal concepts be based in some way or other in the ultimately simple concepts. Grue is based in the physical, but there is no presumption of simple and strong generalizations governing grue. I don't know how to say in general what kind of basing is "appropriate", in order for presumptions of simplicity about the basis to "trickle up", generating presumptions of simplicity about the based; but the lesson of grue suggests that disjunctive basing blocks the trickling up. Thus, for example, if my own view (Sider, 20 I I,

\footnotetext{
${ }^{16}$ These concepts might be, but needn't be, metaphysically fundamental, since the ultimacy is epistemic: the presumption of simplicity is underived from other such presumptions. For example, perhaps there are ultimate presumptions of simplicity for certain higher-level specialscience concepts. This wouldn't require saying that special-science concepts are fundamental, though it would be naturally paired with the idea that special-science lawhood cannot be explained merely by appeal to physical lawhood.
} 
chapter I2) about how modal concepts are based in nonmodal concepts is correct, we should not expect simple laws governing modal concepts. In my view, for a proposition to be necessary is for it to be true and fall under one of a certain list of types, where the items on the list are heterogeneous and given more or less conventionally. ${ }^{17}$ Even given presumptions of simplicity for the concepts in the list, there would be no presumption of simplicity for modality itself, since it's defined disjunctively via the list.

Lewis's (I986) identification of necessity with truth at all concrete worlds might seem less disjunctive and thus more friendly to the presumption. But his counterpart-theoretic reduction of modality de re generates hidden complexity in modal logic. ${ }^{18}$ And in any case, there is a sense in which Lewis's modal realism is already necessitist, obviating the need for Williamson's argument. ${ }^{19}$ (There is also the point that Lewis's modal realism is surely false.)

Perhaps there is some other reduction of necessity on which necessity would be appropriately based in ultimately simple concepts. But I suspect a more likely position for a defender of Williamson's argument is that necessity and possibility are metaphysically fundamental. Modal concepts are, after all, notoriously resistant to reduction; even reductionists like me should admit this. Given such a position, it would be natural to hold that modal concepts are ultimately simple - that there is an ultimate presumption of simplicity for modal concepts, just as there is an ultimate presumption of simplicity for physical concepts. My argument thus rests on rejecting this "modalist" position.

\footnotetext{
${ }^{17}$ Note that my account of necessity is limited in crucial ways-it does not cover iterations of modal operators, for example-and therefore would need to be extended in order to make contact with Williamson's argument, which involves the logic of second order quantified modal logic. But on any way of extending it, necessity would remain disjunctive in the relevant sense.

${ }^{18}$ See Kripke (1972, p. 45, note I3); Hazen (1979).

${ }^{19}$ See Williamson (2013, p. I6). Williamson's classification of Lewis as a Necessitist might seem to ignore Lewis's (I968) scheme for translating modal formulas. For example, Lewis's translation of $\diamond \exists x F x \rightarrow \exists x \diamond F x$ (an instance of the Barcan schema) into the language of counterpart theory is a false sentence saying that if some L-world (i.e. maximal spatiotemporally interrelated object) contains an $F$ then there is an $F$ in this L-world. Williamson would complain that the translation treats the quantifiers in the modal formula as restricted, whereas Necessitism concerns unrestricted quantification. Though I think that calling Lewis a Necessitist is unnecessarily confrontational (Lewis would insist that ordinary modal claims are to be interpreted in his way, and why fight about that?), I do think that the classification is fair insofar as the issue is what Williamson cares about most: access to full second-order modal reasoning. Since Lewis's translation scheme is contingentist it will sometimes interfere with modal second order reasoning, but then Lewis will be happy to suspend the translation scheme, as he always did when it caused trouble (Lewis, I986, pp. I2-I3).
} 
This issue is large in scope, and I won't pretend to settle it here. All-toobriefly and superficially: my rejection of modalism is based on the conviction that modal concepts do not have the theoretical "track record of success" that good candidates for being metaphysically fundamental ought to have. In addition to being "reduction-resistant", physical, logical, and mathematical concepts are essential to theories that have been immensely successful at explaining phenomena. The same cannot be said of modal concepts, in my view.

But my opponent may urge that modal concepts $d o$ have the required track record: in metaphysics, perhaps; or in ordinary counterfactual reasoning; or, finally, in possible-worlds semantics for natural language. I'll consider these arenas in turn.

Williamson says that "For quantified modal logic in particular, one of its many roles is to supply a central structural core to theories of modal metaphysics." (p. x) Perhaps modal metaphysics has a track record of success that justifies our acceptance of modality at the fundamental level.

There is no question that, in comparison to many other approaches to metaphysics, anyway, modal metaphysics has been a successful research program. The metaphysical boom since the seventies is evidence for this. But many have recently been challenging the hegemony of the modal approach to metaphysics. ${ }^{20}$

Some of these challenges, though, are merely to the completeness of the modal approach. If modality is merely to be supplemented by the favored concepts of the challengers—-ground, essence, or building — it may still be part of a successful metaphysical research program, and thus have a claim to fundamentality.

Moreover, even if modality is to be replaced rather than supplemented, this would not on its own evade the challenge of Williamson's argument. Suppose Fine convinced us to replace modality with his notion of essence, in our metaphysical endeavors. We would still have the notion of necessity: to be necessary, according to Fine, is to hold in virtue of the essences of all things (1994, p. 9). This is a direct and nondisjunctive definition of necessity in terms of Fine's essentialist operator "it is true in virtue of the essences of such-and-such entities that $A$ ", and so Williamson's argument might retain its force. ${ }^{21}$

But I myself think that modality ought to be replaced in metaphysical

\footnotetext{
${ }^{20}$ See, for instance, Fine (1994, 200I, 201 2); Schaffer (2009); Rosen (2010); Bennett (2017).

${ }^{21}$ Note that Fine takes the quantifiers to be "possibilist" in Fine (1995), his formal development of the logic of essence- "for the sake of simplicity", he says (p. 244).
} 
inquiry in a more radical way: by a notion of fundamentality from which there is no immediate and nondisjunctive method for recovering the notion of modality (Sider, 20I I). In my view, the putative explanatory successes of modal metaphysics are either illusory or else may be bettered by broadly fundamentality-theoretic metaphysical explanations.

There is a more basic concern with supporting the fundamentality of modality by its track record within metaphysics: a track record in that arena can only be so impressive. Metaphysics, after all, is a deeply speculative field.

Here I find myself struck again by the parallel between Modal Logic as Metaphysics and On the Plurality of Worlds. Both Williamson and Lewis draw their ontological conclusions - the former of a domain of contingently nonconcrete entities, the latter of an amodal domain of concrete "possibilia"-from a premise that the subject matter of modality ought to be theorized in a certain way. For Williamson the premise is that the logic of possibility and necessity, when combined with second-order quantification theory, should be simple and powerful; for Lewis the premise is that the theory of modality should be simple and powerful but also parsimonious in a certain way, and thus free of primitive modal notions. Lewis famously met incredulous stares, and Williamson probably gets them too. What I suspect is that the incredulous stare comes from a concern with drawing radical ontological conclusions on the basis of promised theoretical successes in modal metaphysics, an area of unclear theoretical value.

Even if modal metaphysics is granted to have a weaker track record than, say, successful scientific theories, it may be argued that it has a strong enough track record to justify some confidence in the fundamentality of modal concepts. While this may generate only weak confidence in Williamson's conclusion, that's something he could live with; it is unsurprising, after all, to have weaker confidence in metaphysical conclusions than in scientific conclusions.

However, we must take into account countervailing pressures on our beliefs: there is surely some sort of presumption to minimize ontology. Now, in a discussion of the necessity and permanence of identity, Williamson in fact addresses the question of what to do when ontological parsimony clashes with modal logic:

For the necessitist or permanentist to mess with the modal or temporal logic of identity in order to avoid ontological inflation would be a lapse of methodological good taste, or good sense, for it means giving more weight to ontology than to the vastly better developed and more successful discipline of logic. (pp. 26-7) 
While I agree that there is something to Williamson's claim that logic is vastly better developed and more successful than ontology, the truth of the claim depends, I think, on what exactly one means by 'logic' and 'ontology'. Logic as a whole has an undeniably powerful track record-much of it in the sciences and mathematics, in which logical notions and logical inference are indispensablebut the track record of modal logic is far less impressive, being mostly within philosophy. And as for ontology: ontology as a whole, inquiry into what there is, includes questions like whether there are black holes, comets, and electrons, and thus has an excellent track record. To discount the importance of parsimony in the present context would require, for the purpose of evaluating track records, simultaneously grouping modal logic with nonmodal logic and grouping philosophical ontology apart from nonphilosophical ontology. Each strikes me as problematic, and the two together even more so.

Let's now leave the arena of metaphysics, and look elsewhere for a track record of success for modal concepts. It may be proposed that our successful practice of reasoning counterfactually, in ordinary, nonphilosophical contextsstressed by Williamson himself in The Philosophy of Philosophy — gives the needed track record. Also there is the semantics of natural language, in which possible worlds have been undeniably valuable. Each of these two nonmetaphysical arenas provides a formidable argument that modal concepts do have a track record of success. Still, there is room for doubt.

Something about the structure of possible worlds semantics is undeniably explanatory: it is fruitful to think of thought and discourse using a space of entities that in some sense count as possibilities. But it is less clear that the quality of the explanations in possible worlds semantics rests on the "possibilities" in question really counting as possibilities in any deep sense. Robert Stalnaker's longstanding attitude toward possible-worlds explanations comes to mind here: he argues that it is not important for there to be a once-and-for-all space of possibilities; we need only a conception of possibilities adequate for the modeling purposes at hand. ${ }^{22}$ Similarly, I would argue, though it's clearly fruitful for creatures like us to reason counterfactually, the quality of the practice of counterfactual reasoning is largely insensitive to the nature of the background space of possibilities, since what does the bulk of the explanatory work is the similarity metric on that space, or the contextual restriction on possibilities in the space, depending on one's views about the semantics of counterfactuals. ${ }^{23}$

\footnotetext{
${ }^{22}$ See, for example, Stalnaker (1986).

${ }^{23}$ See Sider (20I I, section I 2.I 2) on a related issue. For the two approaches to counterfactuals
} 
Thus it is unclear whether the concepts of possibility and necessity themselves deserve credit for the successes of possible worlds semantics and counterfactual reasoning.

Taking this line is a little uncomfortable, though. Compare the argument that mathematical entities must be accepted because our best physical theories quantify over them (Putnam I97 I; Quine I95 I, section 6; I960, chapter 7). Even if it is possible to paraphrase away the quantification, or to take it instrumentally, that doesn't on its own answer the argument, for the more straightforwardly interpreted theory may be superior, on general theoretical grounds, to the paraphrased or instrumentalist replacements. The Stalnakerian attitude toward the successes of possible-worlds semantics and counterfactual reasoning are similar, and an opponent may make the same complaint.

\section{References}

Bennett, Karen (20I 7). Making Things Up. Oxford: Oxford University Press.

Cameron, Ross P. (2010). "How to Have a Radically Minimal Ontology." Philosophical Studies I 5 I: 249-64.

Chalmers, David J., David Manley and Ryan Wasserman (2009). Metametaphysics. Ed. David J. Chalmers, David Manley and Ryan Wasserman. Oxford: Oxford University Press.

Cresswell, Max (I99I). "In Defence of the Barcan Formula." Logique Et Analyse I35(I36): 27 I-282.

Dasgupta, Shamik (20I4). "The Possibility of Physicalism." Fournal of Philosophy I I I : 5 57-92.

Dorr, Cian (2005). "What We Disagree About When We Disagree About Ontology." In Mark Kalderon (ed.), Fictionalism in Metaphysics, 234-86. Oxford: Oxford University Press.

- (2007). "There Are No Abstract Objects." In Theodore Sider, John Hawthorne and Dean W. Zimmerman (eds.), Contemporary Debates in Metaphysics, 32-63. Oxford: Blackwell.

alluded to in the text, see Stalnaker (1968) and Lewis (1973) on the similarity approach, and Lycan (200I) and von Fintel (200I) on the contextualist approach. 
Fine, Kit (1977). “Postscript.” In Worlds, Times, and Selves. London: Duckworth. - (1985). "Plantinga on the Reduction of Possibilist Discourse." In J. Tomberlin and Peter van Inwagen (eds.), Alvin Plantinga, I45-86. Dordrecht: D. Reidel.

— (I994). "Essence and Modality." In Tomberlin (I994), I-I6.

- (1995). "The Logic of Essence." Fournal of Philosophical Logic 24: 24I-73.

- (200I). "The Question of Realism." Philosophers' Imprint I: I-30.

- (2009). "The Question of Ontology." In Chalmers et al. (2009), I 57-77.

- (2012). "Guide to Ground." In Fabrice Correia and Benjamin Schnieder (eds.), Metaphysical Grounding: Understanding the Structure of Reality, 37-80. Cambridge: Cambridge University Press.

Goodman, Nelson (1955). “The New Riddle of Induction.” In Fact, Fiction, and Forecast, 59-83. Cambridge, MA: Harvard University Press.

Harper, William L., Robert Stalnaker and Glenn Pearce (eds.) (I98I). Ifs: Conditionals, Belief, Decision, Chance, and Time. Dordrecht: D. Reidel.

Hazen, Allen (1979). "Counterpart-Theoretic Semantics for Modal Logic." 7ournal of Philosophy 76: 319-38.

Kripke, Saul (1972). "Naming and Necessity." In Donald Davidson and Gilbert Harman (eds.), Semantics of Natural Language, 253-355, 763-9. Dordrecht: D. Reidel. Revised edition published in 1980 as Naming and Necessity (Harvard University Press, Cambridge, MA).

Lewis, David (1968). "Counterpart Theory and Quantified Modal Logic." Fournal of Philosophy 65: I $_{3} 3^{-26}$. Reprinted in Lewis I983: 26-46.

- (I973). Counterfactuals. Oxford: Blackwell.

— (1983). Philosophical Papers, Volume I. Oxford: Oxford University Press.

- (1986). On the Plurality of Worlds. Oxford: Blackwell.

Linsky, Bernard and Edward N. Zalta (1994). "In Defense of the Simplest Quantified Modal Logic.” In Tomberlin (I994), 43 I-58. 
- (1996). "In Defense of the Contingently Nonconcrete." Pbilosophical Studies 84: $283-94$.

Loux, Michael J. (ed.) (1979). The Possible and the Actual. Ithaca, NY: Cornell University Press.

Lycan, William (200I). Real Conditionals. Oxford: Oxford University Press.

Plantinga, Alvin (1976). "Actualism and Possible Worlds." Theoria 42: I39-6o. Reprinted in Loux 1979: 253-73.

- (1983). "On Existentialism." Philosophical Studies 44: I-20. Reprinted in Plantinga 2003: $15^{8-75}$.

- (2003). Essays in the Metaphysics of Modality. Ed. Matthew Davidson. New York: Oxford University Press.

Putnam, Hilary (1971). Philosophy of Logic. New York: Harper \& Row.

Quine, W. V. O. (195I). “Two Dogmas of Empiricism.” Philosophical Review 6o: 20-43. Reprinted in Quine 1953: 20-46.

- (1953). From a Logical Point of View. Cambridge, MA: Harvard University Press.

— (1960). Word and Object. Cambridge, MA: MIT Press.

Rosen, Gideon (2010). "Metaphysical Dependence: Grounding and Reduction." In Bob Hale and Aviv Hoffmann (eds.), Modality: Metaphysics, Logic, and Epistemology, 109-36. Oxford: Oxford University Press.

Salmon, Nathan (1998). "Nonexistence." Nô̂s 32: 277-319.

Schaffer, Jonathan (2009). "On What Grounds What." In Chalmers et al. (2009), 347-83.

Sider, Theodore (2009). "Ontological Realism." In Chalmers et al. (2009), 384-423.

- (201 I). Writing the Book of the World. Oxford: Clarendon Press.

— (2013a). "Reply to Jonathan Schaffer." Analysis 73: 760-70. 
- (2013b). "Reply to Kit Fine." Philosophy and Phenomenological Research 88: $73^{8-46 .}$

Stalnaker, Robert (1968). "A Theory of Conditionals." In James Cornman (ed.), Studies in Logical Theory: American Philosophical Quarterly Monograph Series, No. 2, 98-I I 2. Oxford: Blackwell. Reprinted in Harper et al. I98 I: 4I-56.

- (1986). "Possible Worlds and Situations." Fournal of Philosophical Logic I 5(r): I09-I 23.

Tomberlin, James (ed.) (1994). Philosophical Perspectives 8: Logic and Language. Atascadero, CA: Ridgeview.

von Fintel, Kai (200I). "Counterfactuals in a Dynamic Context." In Ken Hale: A Life in Language, I23-52. Cambridge, MA: MIT Press.

Weatherson, Brian (2003). "What Good Are Counterexamples?” Philosophical Studies I I5: I-3 I.

Williamson, Timothy (1998). "Bare Possibilia." Erkenntnis 48: 257-73.

- (2000). "Existence and Contingency." Proceedings of the Aristotelian Society Iо0: 32 I-43. Corrected version of original article from Proceedings of the Aristotelian Society Supplementary Volume 73 (I999), pp. I8 I-203.

- (2002). "Necessary Existents." In A. O'Hear (ed.), Logic, Thought and Language, 233-5 I. Cambridge: Cambridge University Press.

- (2007). The Philosophy of Philosophy. Malden, MA: Blackwell.

— (2013). Modal Logic as Metaphysics. Oxford: Oxford University Press. 